\title{
Matérista
}

Revista Matéria, v. 13, n. 3, pp. 488 - 494, 2008

ISSN 1517-7076

http://www.materia.coppe.ufrj.br/sarra/artigos/artigo10834

\section{Avaliação de revestimentos para proteção contra a descarbonetação de tijolos refratários MgO-C durante o aquecimento de panelas de aciaria}

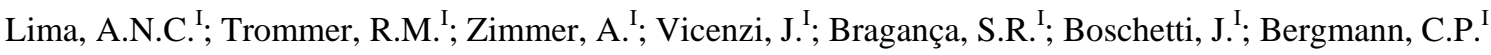 \\ I Laboratório de Materiais Cerâmicos - LACER - UFRGS, Avenida Osvaldo Aranha, 99/705C, \\ 90.035-190, Porto Alegre, RS. \\ e-mail: álvaro_niedersberg@yahoo.com.br, rafael_trommer@yahoo.com.br, zimmer@ufrgs.br, \\ jvicenzi@ufrgs.br, saulorb@ufrgs.br, joão.boschetti@gerdau.com.br, bergmann@ufrgs.br
}

\section{RESUMO}

Este trabalho tem como objetivo avaliar a proteção contra a descarbonetação de diferentes revestimentos de pintura de tijolos refratários $\mathrm{MgO}-\mathrm{C}$ usados em panelas de aciaria. A oxidação de tijolos refratários MgO-C leva à perda de espessura dos tijolos e, conseqüentemente, à diminuição da vida útil dos mesmos. Neste trabalho, foram testados três tipos de revestimentos (A, B e C), preparados em laboratório, os quais foram aplicadas sobre tijolos $\mathrm{MgO}-\mathrm{C}$. Estes revestimentos foram testados em relação à proteção contra a descarbonetação nas temperaturas de 850,950 e $1050^{\circ} \mathrm{C}$. A partir dos resultados obtidos, verificou-se que a aplicação de revestimentos para pintura sobre refratários MgO-C apenas minimiza a descarbonetação, já que estes revestimentos vitrificam em temperaturas superiores ao início da oxidação. Além disso, notou-se que a espessura da camada descarbonetada é diretamente proporcional à temperatura de queima. Entre os revestimentos avaliados, o que apresentou melhores resultados foi o $\mathrm{C}$, devido as suas características de escorrimento e viscosidade, além de vitrificar em temperatura inferior a dos revestimentos A e B.

Palavras-chaves: descarbonetação, refratários MgO-C, revestimentos.

\section{Evaluation of coatings for protection against decarburization of refractory bricks MgO-C during heating in steelmaking ladles}

\section{ABSTRACT}

This work aims to evaluate the utilization of different coatings to prevent the decarburization of refractory bricks $\mathrm{MgO}-\mathrm{C}$ used in ladles. This oxidation causes the loss of thickness of the bricks and the reduction of its useful live. The three types of coatings $\mathrm{A}, \mathrm{B}$ e $\mathrm{C}$ were prepared in laboratory and then were applied on MgO-C bricks. The samples were tested at temperatures of $850^{\circ} \mathrm{C}, 950^{\circ} \mathrm{C}$ and $1050^{\circ} \mathrm{C}$. It was verified that the three tested coatings only minimize the decarburization, since they vitrify and become effective at temperatures higher to the beginning of the oxidation temperature. Moreover, it was noticed that the thickness of the decarburized layer is directly proportional to the firing temperature. The coating that presented better results was $\mathrm{C}$, which showed better characteristics of flowing and viscosity. Besides that, it vitrified at lower temperature comparing to coatings $\mathrm{A}$ and the $\mathrm{B}$.

Keywords: decarburization, MgO-C bricks, coatings.

\section{INTRODUÇÃO}

Uma das maiores causas do desgaste nos tijolos refratários de uma panela de aciaria é a descarbonetação que ocorre durante o pré-aquecimento e o reaquecimento das panelas, fazendo com que a posterior presença de aço ou escória degrade o tijolo refratário. Após a montagem da panela (fundo, parede, linha e sobre linha de escória), é necessário o pré-aquecimento dessa para receber o aço em temperaturas elevadas, evitando, assim, um possível choque térmico dos tijolos refratários, bem como o resfriamento do aço. Durante o pré-aquecimento e, também, nos reaquecimentos, a atmosfera no interior da panela causa a descarbonetação do tijolo refratário. Isto ocorre porque a relação ar/gás combustível, utilizado para aquecer a panela, torna a atmosfera possivelmente oxidante, causando a oxidação (descarbonetação) dos tijolos refratários [1]. Esta descarbonetação causa a diminuição da espessura do tijolo e, assim, é preciso utilizar um material que apresente condições para satisfazer a necessidade de minimizar ou então impedir a 
descarbonetação dos tijolos refratários durante o aquecimento da panela. Atualmente, a solução encontrada é utilizar argamassas refratárias para pintura de modo a minimizar esse efeito.

Neste trabalho, buscou-se avaliar a proteção das diferentes argamassas de pintura contra a descarbonetação de tijolos refratários MgO-C da linha de escória de panelas de aciaria que produzem aços especiais na Gerdau Aços Especiais Piratini.

Essas argamassas de pintura, ou revestimentos de proteção, são vidradas compostas de silicatos e óxidos. Os vidrados de silicatos têm sua viscosidade bastante reduzida em relação aos vidros de sílica. Sua estrutura e propriedades dependem da natureza dos óxidos adicionados. Os óxidos modificadores de rede, como os dos metais alcalinos e alcalino-terrosos, quebram, gradualmente, a rede de sílica, tanto mais quanto mais são adicionados. $\mathrm{O}$ aporte destes óxidos é geralmente feito na forma de carbonatos [2]. A adição de óxidos de metais alcalinos diminui a resistência química do vidrado e, em altas concentrações, esse poderá ser solúvel em água [3]. Para reduzir a solubilidade dos vidrados de silicatos alcalinos, sem perder a facilidade de fusão, são adicionados fluxos estabilizantes, como o cálcio e o magnésio. Os vidrados sódiocálcicos contêm, normalmente, entre 8 e $12 \%$ em peso de óxido de cálcio e entre 12 e $17 \%$ em peso de um óxido alcalino (óxido de sódio). Maiores quantidades de óxido de cálcio podem levar à cristalização do vidrado durante sua aplicação. Usualmente, é empregada uma pequena quantidade de alumina (0,6 a 2,5\%) para aumentar a resistência química do vidro. Muitas das propriedades dos vidrados dependem de suas características estruturais, que, por sua vez, estão condicionadas à composição química e, em menor escala, ao processamento térmico a que foi submetido [3]. A variação das propriedades com a composição pode ser avaliada, com certa aproximação, em função da concentração dos componentes. Por exemplo, aumentando-se o óxido de sódio, há um aumento da fluidez, da expansão e da solubilidade do vidrado, mas, por outro lado, há uma diminuição da sua resistência química. A alumina aumenta a resistência química e a viscosidade do vidro, já o óxido de cálcio favorece a devitrificação [4].

\section{MATERIAIS E MÉTODOS}

Os revestimentos estudados foram denominados A, B e C.

Estes revestimentos foram caracterizados quanto às suas propriedades físicas e químicas: distribuição granulométrica por difração a laser $\left(\right.$ CILAS $^{\circledR}$, modelo 1180), viscosidade (BROOKFIELD ${ }^{\circledR}$, modelo RVDVII+, haste modelo RV7 com velocidade de rotação de $100 \mathrm{rpm}$ a temperatura ambiente $26^{\circ} \mathrm{C} \pm$ $1^{\circ} \mathrm{C}$ ) e análise química por fluorescência de raios-X (SHIMADZU ${ }^{\circledR}$, modelo XRF-1800). As amostras foram testadas em relação à proteção contra a descarbonetação nas temperaturas de 850,950 e $1050^{\circ} \mathrm{C}$ (forno tipo mufla). Foi avaliada, também, a sua viscosidade em função da temperatura. Para a realização deste ensaio, utilizou-se uma base com inclinação de $45^{\circ}$, com três cavidades, onde são colocadas as amostras a serem avaliadas, que, ao fundirem, deslizam sobre a parede e, a partir desse deslizamento, faz-se a medida em centímetros do escorrimento ocorrido. As amostras foram preparadas da mesma forma que as utilizadas para a aplicação sobre os refratários, conformadas na forma de esfera e colocadas nas cavidades da base cerâmica, após foram colocadas em estufa a $110^{\circ} \mathrm{C}$ por 24 horas. Por fim, a base com as amostras foi aquecida em forno tipo mufla a $1050^{\circ} \mathrm{C}$ com patamar de 30 minutos e taxa de aquecimento de $120^{\circ} \mathrm{C} / \mathrm{min}$. Após o aquecimento, avalia-se o escorrimento em centímetros a partir da base de cada amostra. A Figura 1 apresenta o fluxograma da metodologia utilizada.

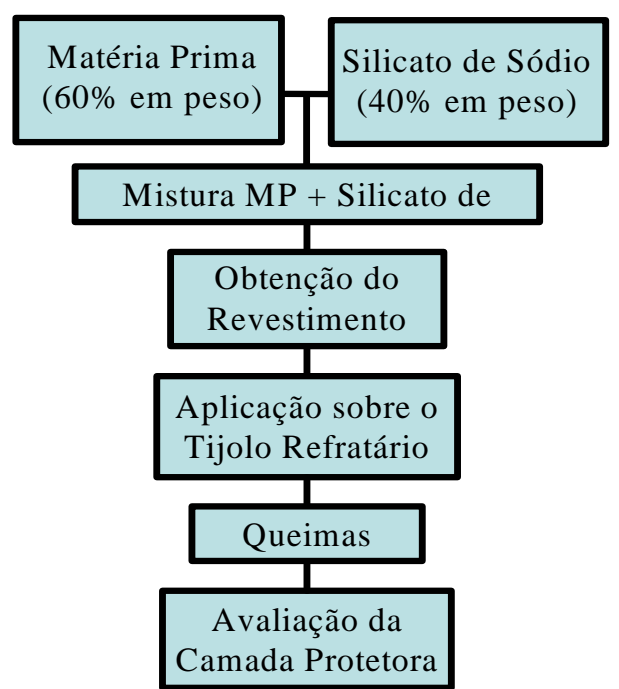

Figura 1: Fluxograma dos ensaios realizados. 


\section{RESULTADOS E DISCUSSÕES}

A Tabela 1 apresenta a composição química dos revestimentos estudados para proteção contra descarbonetação, obtida por fluorescência de raios-X.

Tabela 1: Composição química dos revestimentos A, B e C obtida por fluorescência de raios-X.

\begin{tabular}{c|ccc}
\hline Óxidos (\% em peso) & $\mathbf{A}$ & $\mathbf{B}$ & $\mathbf{C}$ \\
\hline $\mathrm{SiO}_{2}$ & 54,56 & 33,89 & 61,74 \\
$\mathrm{PbO}$ & - & 35,98 & - \\
$\mathrm{ZrO}_{2}$ & 27,92 & 15,73 & - \\
$\mathrm{Al}_{2} \mathrm{O}_{3}$ & 9,02 & 7,59 & 20,21 \\
$\mathrm{CaO}$ & 3,68 & 2,18 & 3,34 \\
$\mathrm{MgO}$ & 1,63 & 0,51 & 1,19 \\
$\mathrm{Na}_{2} \mathrm{O}$ & 1,11 & 0,5 & 4,28 \\
$\mathrm{~K}_{2} \mathrm{O}$ & 0,83 & 0,68 & 2,03 \\
$\mathrm{SnO}_{2}$ & - & 1,73 & - \\
$\mathrm{P}_{2} \mathrm{O}_{5}$ & 0,67 & - & 5,68 \\
$\mathrm{Fe}_{2} \mathrm{O}_{3}$ & 0,37 & 0,4 & 0,53 \\
$\mathrm{TiO}_{2}$ & 0,17 & 0,7 & 0,99 \\
$\mathrm{BaO}$ & 0,01 & 0,1 & - \\
$\mathrm{Total}$ & 100 & 99,99 & 99,99 \\
\hline
\end{tabular}

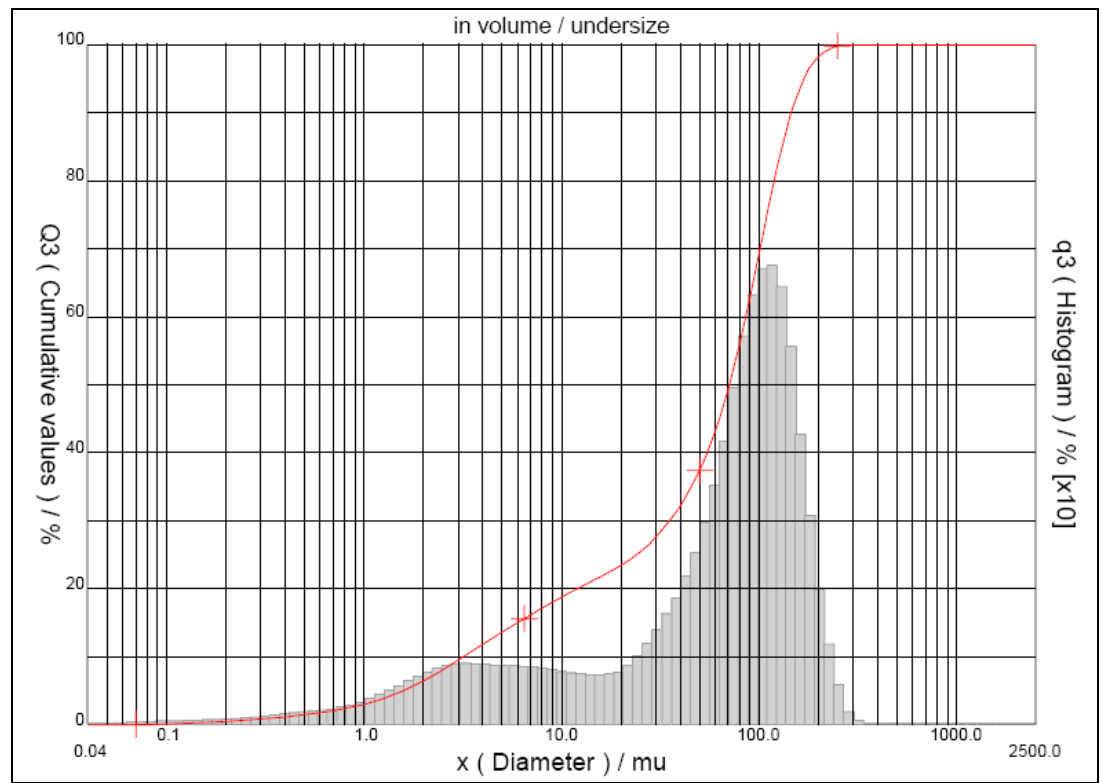

Figura 2: Distribuição granulométrica de tamanhos de partículas por difração a laser do revestimento C.

Através da análise da Tabela 1, observa-se que o revestimento C é composto, majoritariamente, por óxidos de silício, alumínio, fósforo, cálcio e sódio; o revestimento B, por óxidos de silício, chumbo, zircônio e alumínio; enquanto o revestimento A, por óxidos de silício, zircônio e alumínio. Observa-se, então, uma mudança dos óxidos modificadores da rede, que tendem a controlar propriedades do vidrado como o ponto de 
amolecimento e sua temperatura de transição vítrea. Dessa forma, pode-se inferir que devido à maior quantidade de $\mathrm{CaO}$ no revestimento $\mathrm{A}$, esse não apresenta uma boa vitrificação em temperaturas mais baixas, tendo em vista que esse óxido apresenta um caráter refratário, favorecendo a descarbonetação do refratário de MgO-C. Por outro lado, o revestimento $\mathrm{C}$ apresenta quantidades significativas de $\mathrm{Na}_{2} \mathrm{O}$ e $\mathrm{K}_{2} \mathrm{O}$, que favorecem sua fluidez. Já no caso do revestimento B, essa fluidez é facilitada pela presença de grande quantidade de $\mathrm{PbO}$.

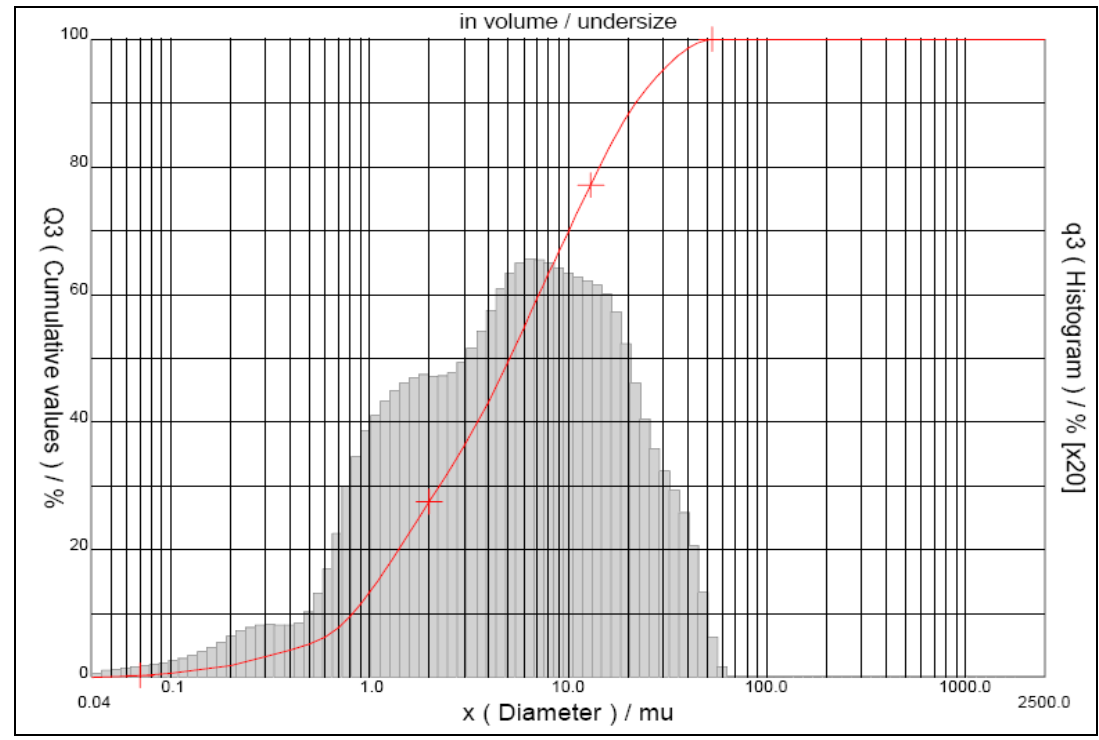

Figura 3: Distribuição granulométrica de tamanhos de partículas por difração a laser do revestimento A.

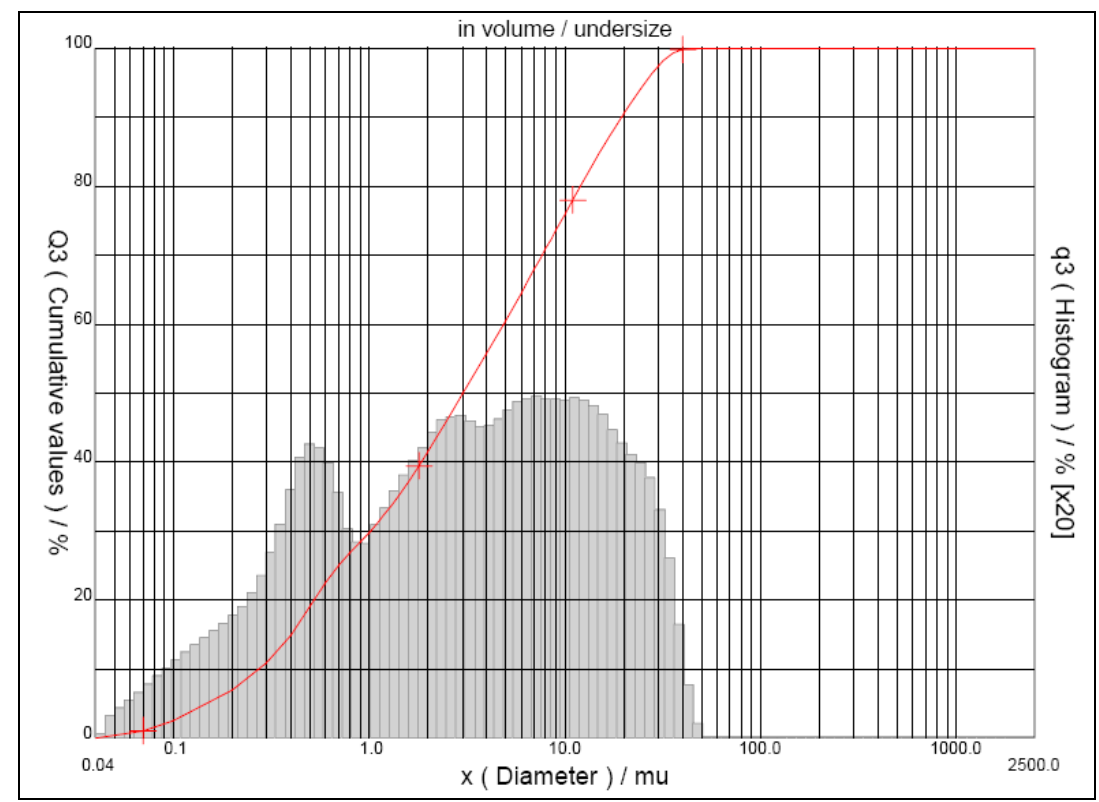

Figura 4: Distribuição granulométrica de tamanhos de partículas por difração a laser do revestimento B.

Tabela 2: Distribuição granulométrica dos revestimentos A, B e C obtida por difração a laser.

\begin{tabular}{c|cccc}
\hline Revestimento & $\mathrm{D}_{\text {médio }}(\mu \mathrm{m})$ & $\mathrm{D}_{10}(\mu \mathrm{m})$ & $\mathrm{D}_{50}(\mu \mathrm{m})$ & $\mathrm{D}_{90}(\mu \mathrm{m})$ \\
\hline $\mathrm{A}$ & 8,65 & 0,82 & 5,09 & 21,92 \\
$\mathrm{~B}$ & 6,72 & 0,27 & 3,01 & 19,55 \\
$\mathrm{C}$ & 73,2 & 3,17 & 70,98 & 145,91 \\
\hline
\end{tabular}


Pela análise das Figuras 2, 3 e 4 e da Tabela 2, constata-se que o revestimento C apresenta uma distribuição de tamanho trimodal, com freqüências semelhantes para cada uma das 3 distribuições que se sobrepõem. Isso, provavelmente, propicia um melhor recobrimento da superfície do material refratário, durante sua aplicação sobre o refratário. Pode-se, também, observar um caráter trimodal para o revestimento B, porém com freqüências bem distintas para cada faixa granulométrica e com tamanho médio de suas partículas bem inferior ao do revestimento C. Já o revestimento A apresenta caráter bimodal com tamanho médio de partícula intermediário ao $\mathrm{C}$ e $\mathrm{B}$.

Além de um bom recobrimento do revestimento na aplicação, é importante que o revestimento escorra na superfície do refratário de maneira adequada, suficiente para cobrir toda a superfície, e não muito fluido, a ponto de escorrer e deixar pontos sem recobrir. Nesse sentido, fez-se o ensaio de escorrimento de cada revestimento na temperatura de $1050^{\circ} \mathrm{C}$, temperatura essa em que os refratários são pré-aquecidos na panela de aciaria. A Figura 5 apresenta os resultados do teste e, por sua análise, verificou-se que entre esses materiais o que apresentou maior escorrimento a $1050^{\circ} \mathrm{C}$ foi o revestimento $\mathrm{B}$, seguido do revestimento $\mathrm{C}$ e $\mathrm{o}$ revestimento A não apresentou escorrimento nessa temperatura. Logo, o revestimento com melhores qualidades de escorrimento, na temperatura estudada, é o C, visto que ele escorre o suficiente para proteger o refratário de MgO-C contra a descarbonetação. Certamente, a alta viscosidade do revestimento A na temperatura de ensaio, não possibilitando o escorrimento para o recobrimento protetivo do refratário, acarretou na significativa descarbonetação desse.

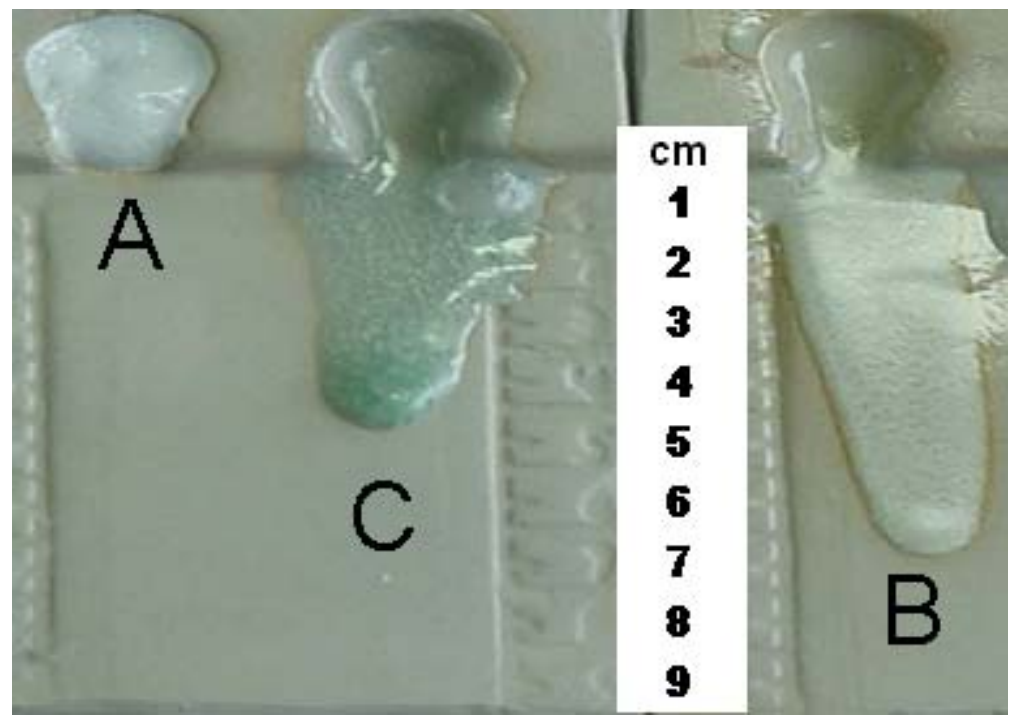

Figura 5: Ensaio de escorrimento dos revestimentos estudados.

Após a proteção em corpos refratários com os revestimentos testados e pré-aquecimento em laboratório, fez-se a análise da seção transversal dos três materiais ensaiados, visando verificar a proteção de cada um contra a descarbonetação, em relação à temperatura. Os resultados estão sumarizados na Figura 6.

Observando a Figura 6, nota-se que independentemente do material utilizado contra a oxidação dos tijolos, o aumento da temperatura implica em um aumento da camada descarbonetada. A maior camada descarbonetada foi atingida na temperatura de $1050^{\circ} \mathrm{C}$, utilizando como proteção o revestimento A. Já a menor camada descarbonetada foi a $850^{\circ} \mathrm{C}$, utilizando o revestimento C. Entre os três materiais testados, o C é aquele que apresenta a menor camada descarbonetada para qualquer uma das temperaturas do ensaio, sendo esse o mais adequado na minimização da descarbonetação dos tijolos refratários durante o aquecimento. 

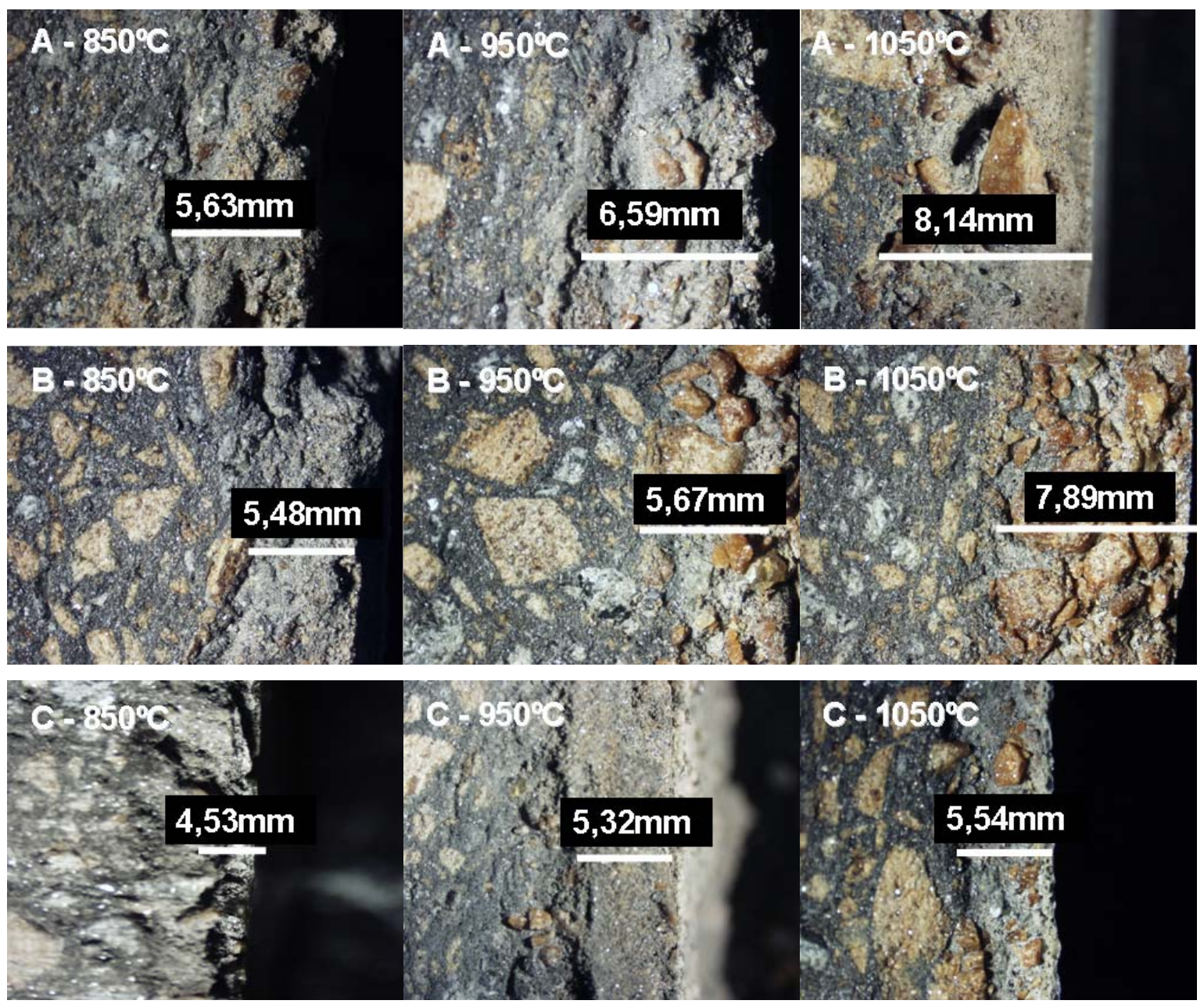

Figura 6: Tijolos refratários revestidos com: A, B e C, e queimados a temperatura de $850^{\circ} \mathrm{C}, 950^{\circ} \mathrm{C}$ e $1050^{\circ} \mathrm{C}$.

\section{4}

\section{CONCLUSÕES}

A partir dos resultados apresentados nesse trabalho, podem-se inferir as seguintes conclusões:

- as análises químicas dos revestimentos mostraram que, devido à maior quantidade de $\mathrm{CaO}$, no revestimento A, esse não apresenta uma boa vitrificação, favorecendo a descarbonetação. A presença de $\mathrm{Na}_{2} \mathrm{O}$ e $\mathrm{K}_{2} \mathrm{O}$ favorecem a fluidez do revestimento $\mathrm{C}$, assim como a presença de grande quantidade de $\mathrm{PbO}$ no revestimento $\mathrm{B}$, o que é comprovado pela análise do escorrimento.

- no teste do escorrimento, apenas o revestimento A não escorreu. Este fato contribui para explicar o porquê que essa amostra teve a maior camada descarbonetada, pois se não há escorrimento na temperatura de trabalho $\left(1050^{\circ} \mathrm{C}\right)$, o revestimento não irá recobrir, satisfatoriamente, o refratário.

- a elevação da temperatura provoca um aumento na espessura da camada descarbonetada. Assim, o revestimento $\mathrm{C}$ foi o que apresentou a menor oxidação ou descarbonetação para as três temperaturas estudadas.

\section{REFERÊNCIAS BIBLIOGRÁFICAS}

[1] GHOSH, N.K., GHOSH, D.N, JAGANNATHAN, K.P, "Oxidation mechanism of MgO-C in air at various temperatures”, British Ceramic Transactions, v. 99, n. 3, pp. 124-128(5), 2000.

[2] WEST, A.R., "Solid-State chemistry and its applications", New York, John Wiley \& Sons, pp. 594 637, 1984 
[3] AKERMAN, M., "Natureza, estrutura e propriedades do vidro”, Centro Técnico de Elaboração de Vidros, Saint Gobain Vidros BRASIL, 2000.

[4] VILLANOVA, D.L., "Processamento cerâmico, evolução microestrutural e controle de propriedades em corpos cerâmicos produzidos à base de cinza pesada de carvão termoelétrico e vidro sodo-cálcico", D.Sc., PPGEMM, UFRGS, Rio Grande do Sul, RGS, Brasil, 2004. 